\title{
Micropatterned Fiber Scaffolds for Spatially Controlled Cell Adhesion
}

\author{
Suparna Mandal, Srijanani Bhaskar, Joerg Lahann*
}

Because the local microstructure plays a pivotal role for many biological functions, a wide range of methods have been developed to design precisely engineered substrates for both fundamental biological studies and biotechnological applications. However, these techniques have been by-and-large limited to flat surfaces. Herein, we use electrohydrodynamic co-spinning to prepare biodegradable three-dimensional fiber scaffolds with precisely engineered, micrometre-scale patterns, wherein each fiber is comprised of two distinguishable compartments. When bicompartmental fiber scaffolds are modified via spatially controlled peptide immobilization, highly selective cell guidance at spatial resolutions $(<10 \mu \mathrm{m})$, so far exclusively reserved for flat substrates, is achieved. Microstructured fiber scaffolds may have utility for a range of biotechnological applications including tissue engineering or cell-based assays.

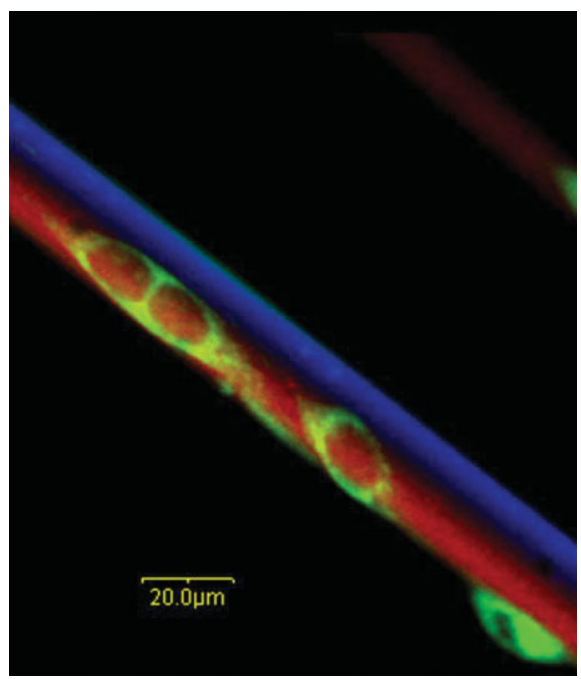

\section{Introduction}

The nano- and microstructure of synthetic materials is a decisive factor related to many biological phenomena, such as cell morphology, adhesion, motility, or apoptosis. ${ }^{[1-7]}$ This relationship has been best established for twodimensional substrates, where a wealth of surface chemis-

J. Lahann

Departments of Chemical Engineering, Materials Science and Engineering, and Macromolecular Science and Engineering, University of Michigan, 48109 (USA)

E-mail: lahann@umich.edu

S. Mandal

Department of Chemical Engineering, University of Michigan, 48109 (USA)

S. Bhaskar

Department of Macromolecular Science and Engineering,

University of Michigan, 48109 (USA) tries have been realized including a wide range of different micro- and nanopatterning methods. ${ }^{\left[{ }^{8-11]}\right.}$ Although studies based on two-dimensional substrates provided valuable, first insight into some of the governing parameters of cell/ substrate interactions, they are intrinsically limited as viable designs for cell culture scaffolds, because they do not account for cells' need of a three-dimensionally controlled microenvironment. ${ }^{[12-16]}$ Toward this end, micro- and nanofibers made of natural and synthetic functional polymers have been extensively used as three-dimensional support structures, ${ }^{[17-22]}$ where local geometry and topography may be as important as materials composition. [23] In spite of undisputable success with fiber-based scaffolds, methods for chemical patterning of three-dimensional fiber scaffolds with biomolecules, such as cell adhesion peptides, are essentially nonexistent. ${ }^{[24]}$

Herein, we demonstrate the synthesis of novel threedimensional fiber scaffolds with micrometer-scale surface patterns that can act as biochemical templates for cellular 
contact guidance. Prepared by electrohydrodynamic co-jetting, the biodegradable poly(lactide-co-glycolide) constructs are comprised of bicompartmental microfibers, where each compartment has an exclusive chemical composition or can be selectively surface-modified. ${ }^{[25]}$ When these aligned multicompartmental fiber scaffolds were used as templates for spatioselective peptide immobilization, a unique type of three-dimensional cell construct was obtained, which exhibited highly selective cell guidance $(p \leq 0.05)$. The herein demonstrated synthesis of multicompartmental fiber scaffolds addresses a critical chemical gap in biotechnology, i.e., micropatterned, yet three-dimensional scaffold architectures, and may have broad utility for a range of biotechnological applications including tissue engineering and cell-based sensors.

\section{Experimental Part}

\section{Materials}

Poly(lactide-co-glycolide) with a lactide:glycolide ratio 85:15 $\left(\bar{M}_{\mathrm{W}}\right.$ 50-75000 $\left.\mathrm{g} \cdot \mathrm{mol}^{-1}\right)$, poly[(m-phenylenevinylene)-alt-(2,5dihexyloxy-p-phenylenevinylene)] (MEHPPV), poly[tris(2,5-bis(hexyloxy)-1,4-phenylenevinylene)-alt-(1,3-phenylenevinylene)] (PTDPV), fluorescein isothiocyanate (FITC), chloroform, and $N, N^{\prime}$ dimethyl formamide (DMF), copper sulfate pentahydrate $\left(\mathrm{CuSO}_{4}{ }^{*} 5 \mathrm{H}_{2} \mathrm{O}\right)$, sodium ascorbate, phosphate buffered saline (PBS), and Tween-20 were purchased from Sigma-Aldrich, USA. $\mathrm{N}_{3}-\mathrm{CH}_{2} \mathrm{CONH}$-CSRARKOAASIKVAVSADR, $\bar{M}_{\mathrm{W}}=2117 \mathrm{~g} \cdot \mathrm{mol}^{-1}$ (peptide-azide) was purchased from ChinaTech Peptide Co, China. Polythiophene polymer ADS 306PT was purchased from American Dye Source, Canada.

\section{Electrohydrodynamic Co-Spinning}

Bicompartmental fibers were prepared from PLGA according to a protocol described elsewhere. ${ }^{[25,26]}$ Scaffolds were jetted on top of either aluminium substrates or glass coverslips mounted on a spinning wheel assembly. For cell adhesion assays, trace amounts of MEH-PPV and PTDPV dyes were added for fluorescent labeling of compartments.

\section{Selective Surface Modification Using Copper-Catalyzed Huisgen Heterocycloaddition}

A microfiber scaffold (length $\approx 2 \mathrm{~cm}$ ) was fixed on the aluminum substrate using tape, and incubated with $150 \mu \mathrm{L}$ of a $0.47 \times 10^{-3} \mathrm{M}$ peptide-azide solution in DI water, $50 \mu \mathrm{L}$ of $0.01 \mathrm{M}$ aqueous $\mathrm{CuSO}_{4} \cdot 5 \mathrm{H}_{2} \mathrm{O}$ solution, followed by $50 \mu \mathrm{L}$ of $1 \mathrm{M}$ aqueous sodium ascorbate solution. The reaction was carried out in $2 \mathrm{~mL}$ of DI water containing $0.01 \% \mathrm{v} / \mathrm{v}$ Tween-20 (Sigma, USA) for $10 \mathrm{~h}$. The unreacted peptide was removed by washing with a $1 \% \mathrm{v} / \mathrm{v}$ Tween-20 in PBS. The fibers were resuspended in DI water and incubated with $10 \mu \mathrm{L}$ of $0.01 \mathrm{~m}$ FITC (dissolved in DMF) for $5 \mathrm{~h}$. The unreacted FITC was removed by repeated washing with $1 \% \mathrm{v} / \mathrm{v}$ Tween-20 in PBS.

\section{Cell Incubation Assay}

NIH 3T3 fibroblasts (ATCC, USA) were cultured in T75 culture flasks in DMEM with $10 \% \mathrm{FCS}$ under $37^{\circ} \mathrm{C} / 5 \% \mathrm{CO}_{2}$ conditions. The cells were passaged at recommended confluence and cells from passages 5-9 were used for all experiments. Glass slides (Fisher Scientific) were modified with polyethylene glycol according to previously reported protocols. ${ }^{[27]}$ Samples with peptide-azide modified microfibers were placed in multi-well plates and a cell suspension in serum-free media was added to the samples at a concentration of $1 \times 10^{5}$ cells $\cdot \mathrm{cm}^{-2}$. Samples were incubated for $6 \mathrm{~h}$ under culture conditions. After $4 \mathrm{~h}$, the samples were imaged using phase contrast microscopy. For confocal imaging, a live-cell actin stain BODIPY-TMR-Cytochalasin D (Invitrogen) was added to the media and the samples were imaged using confocal laser scanning microscopy (CLSM). Quantification of cell adhesion data was performed for five experimental trials by counting number of adhered cells on each microfiber type for a standard length of a single microfiber. Statistical analysis was carried out using a twotailed Students t-test with unequal variance.

\section{Scanning Electron Microscopy (SEM)}

The microfiber scaffolds were spun on top of an aluminium substrate, sputter-coated with gold and their surface morphology was examined by a scanning electron microscope (Philips XL30 ESEM, high vacuum mode).

\section{Confocal Laser Scanning Microscopy (CLSM)}

A FluoView 500 confocal laser scanning microscope (Olympus, Japan) was used to obtain the CLSM images. MEHPPV, PTDPV (and FITC), and BODIPY-TMR-Cytochalasin D (and ADS306PT) were excited by $405 \mathrm{~nm}$ UV, $488 \mathrm{~nm}$ Argon, and $533 \mathrm{~nm}$ Helium-Neon green lasers respectively. Optical filters of emission wavelength 430-460, 505-525, and 560-600 nm were used for fluorescence visualization of MEHPPV, PTDPV (and FITC), and BODIPY-TMRCytochalasin D (and ADS306PT) respectively.

\section{Results and Discussion}

In principle, the electrohydrodynamic co-jetting technology involves laminar flow of at least two different polymeric solutions through a set of capillaries, which are arranged in a side-by-side configuration, ${ }^{[28]}$ as shown by the schematic in Figure 1a. Under these conditions, a welldefined interface can be formed within the pendant droplet. Upon application of a sufficiently high threshold voltage, accumulation of surface charges results in the formation of a liquid cone. ${ }^{[2]}$ The liquid cone acts as the origin of a polymer jet that leads to particle or fiber formation through jet elongation, solvent evaporation, and polymer solidification. After demonstrating the fabrication of bicompartmental nanocolloids from aqueous solutions via the co-jetting process, ${ }^{[30-33]}$ we focused our attention 
a)

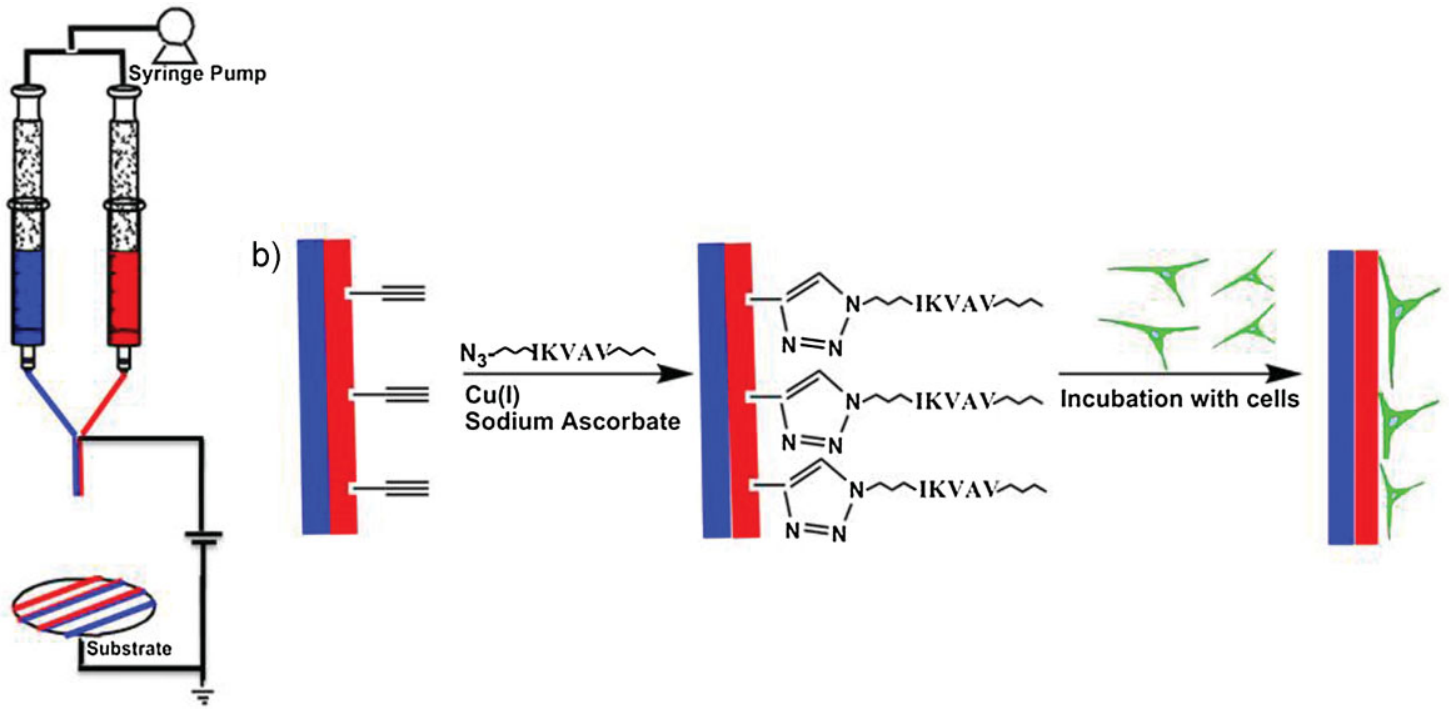

Figure 1. a) Schematic representation of the electrohydrodynamic co-spinning process yielding well-aligned bicompartmental microfiber scaffolds with controllable fiber density. b) Scheme depicting selective surface modification of bicompartmental scaffolds with a celladhesion peptide for spatially guided cell adhesion.

on electrohydrodynamic processing of biodegradable scaffold materials such as poly(lactide-co-glycolide) (PLGA) polymers from organic solvents. ${ }^{[26]}$ In a typical experiment, an 18:100 w/w ratio of PLGA in a 95:5 v/v mixture of chloroform: DMF was pumped through a side-by-side capillary system at a flow rate of $0.02 \mathrm{~mL} \cdot \mathrm{h}^{-1}$ (Figure 1 ). Application of DC potential $(8.1-8.3 \mathrm{kV})$ resulted in droplet stretching, Taylor cone formation, and ejection of a single bicompartmental fiber, which deposited on the counter electrode (Figure $2 a$ and $b$ ). Lower surface charge accumulation tendencies of organic solutions, coupled with a dynamic increase in viscosities due to high volatility of chloroform enhance jet stability, possibly by increasing entanglement effects in the droplet. ${ }^{[34]}$ Consequently, the migration path of the jet is more "linear" and ordered, compared to the curved jet pathways characterized by the well documented bending and kink instabilities. ${ }^{[35]}$ This linear path facilitates the maintenance of a well-defined interface between two solutions during co-spinning for long time periods, thereby providing a platform for the establishment of well aligned scaffolds. Furthermore, flow rates of the order of $0.02-0.03 \mathrm{~mL} \cdot \mathrm{h}^{-1}$ provide a continuous supply of incoming streams, which assists uninterrupted and unfractured fiber production. Taken together, all these factors result in an extremely stable, continuous electrohydrodynamic co-jetting process, which can be sustained up to several hours, yielding bicompartmental fibers with fine interfaces, and well-controlled, narrowly distributed diameters. This is consistent with earlier studies on microfibers ${ }^{[25]}$ and microcylinders. ${ }^{[36]}$ The jet stability developed on account of our jetting solution design thus a)

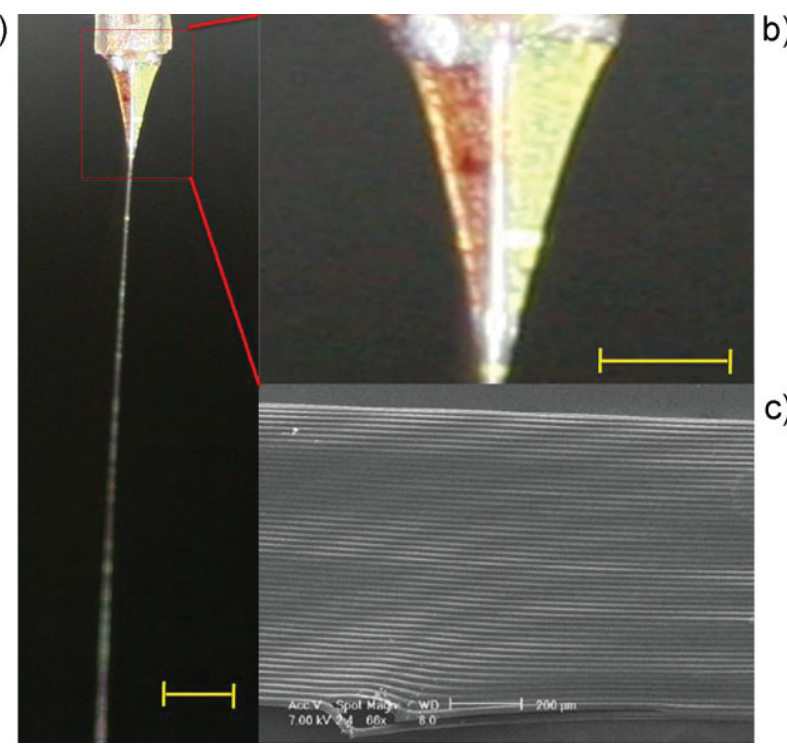

Figure 2. a) Digital photograph of electrohydrodynamic co-spinning of PLGA, yielding a bicompartmental fiber. An 18:100 w/w ratio of PLGA in a 95:5 v/v mixture of cholorform:DMF was employed as the primary jetting solution in both compartments. One solution was loaded with ADS306PT (seen as brown) and the other with MEH-PPV (seen as green). Upon applying a DC potential (8.1-8.3 kV), the droplet distorts to form a liquid cone resulting in the formation a single bicompartmental fiber which deposits on the counter electrode. b) Magnified image of the biphasic droplet with a clear interface between the two solutions which is maintained throughout the process. c) SEM micrograph of a highly aligned fiber sheet, resulting from spinning onto a wheel assembly rotated at $16-18 \mathrm{rpm} \cdot{ }^{[25]}$ The entire length of the sheet spans $3 \mathrm{~cm}$, which equals the diameter of the wheel. The scale bars for $a, b$, and $c$ are $1 \mathrm{~mm}, 500 \mu \mathrm{m}$, and $200 \mu \mathrm{m}$, respectively. 
provides an excellent platform for the establishment of well aligned scaffolds that can be harvested on a variety of substrates with controlled fiber densities and orientations. Figure 2c depicts an SEM micrograph of a highly dense and aligned fiber sheet, resulting from spinning onto a spinning wheel assembly.

The ultimate utility of bicompartmental microfiber scaffolds for cellular contact guidance will depend on their ability to permit micropatterning, i.e., spatially controlled presentation of biological information. To demonstrate the usefulness of bicompartmental microfibers for micropatterning, individual compartments of a bicompartmental microfiber scaffold were surface-modified with a lamininderived cell adhesion peptide. In order to accomplish this, poly[lactide-co-(propargyl glycolide) (acetylene-PLGA) $]^{[26,37]}$ was added to one of the jetting solutions and bicompartmental fibers were prepared. These were reacted via coppercatalyzed Huisgen heterocycloaddition ${ }^{[38,39]}$ with an azidefunctionalized derivative of a laminin-derived peptide, which included a functional IKVAV sequence. To verify that laminin peptide was indeed selectively immobilized to just one of the compartments, primary amino groups of the immobilized peptides were labeled by reaction with the fluorescence probe fluorescein-isothiocyanate (FITC) and subsequently analyzed by CLSM (Figure $3 a$ to $c$ ). Green fluorescence arising from the FITC probe was only observed for the red compartment, i.e., the compartment, which contained acetylene-PLGA (Figure 3a). In a control experiment with bicompartmental microfiber scaffolds containing acetylene-PLGA in both compartments, the peptide was

a)

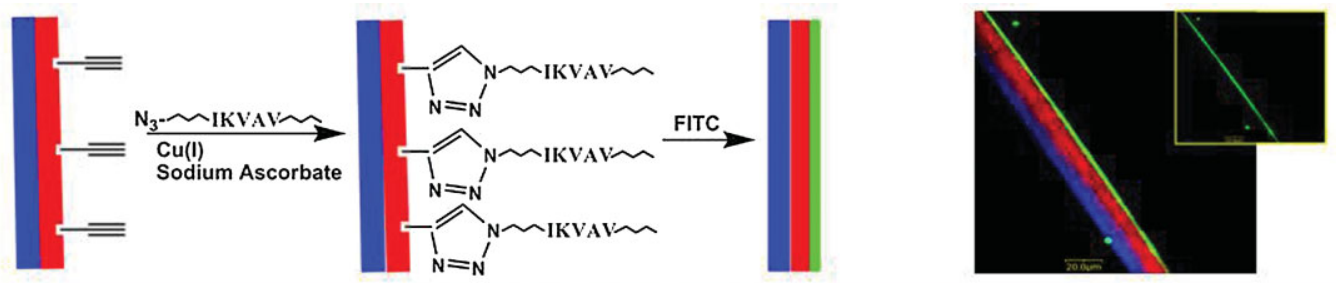

b)

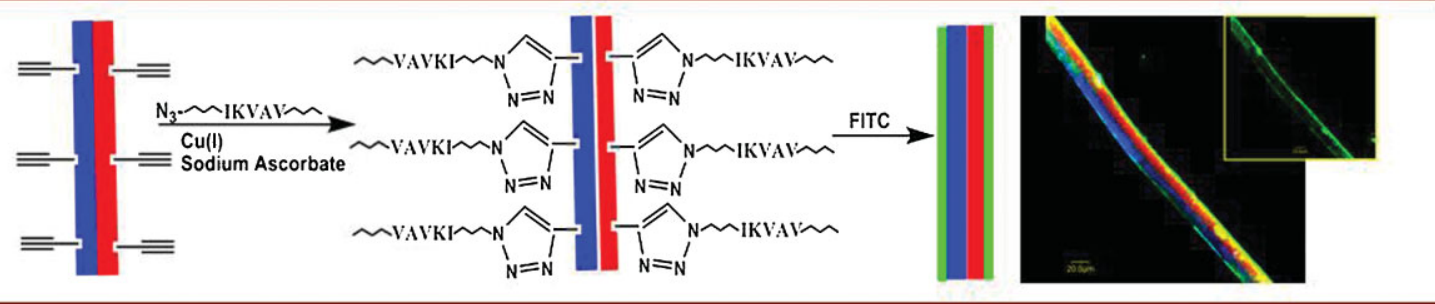

c)
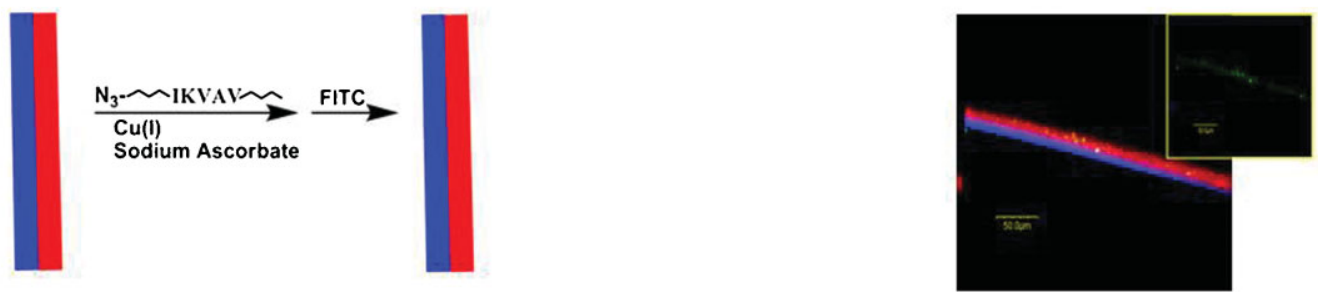

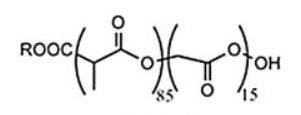

PLGA

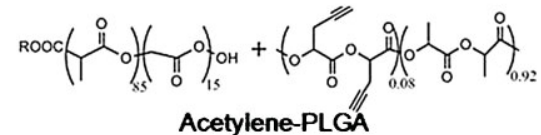

Acetylene-PLGA
$\mathrm{N}_{3}$ - IKVAV $=\mathrm{N}_{3}$-CH2CONH-CSRARKQAASIKVAVSADR Peptide

Figure 3. Scheme and corresponding CLSM micrographs of a series of a bicompartmental microfiber confirming selective surface modification of with an azide-functionalized cell-binding peptide $\left(\mathrm{N}_{3}-\mathrm{CH}_{2} \mathrm{CONH}\right.$-CSRARKOAASIKVAVSADR). Individual CLSM micrographs show blue, green and red fluorescence overlays with inlays representing green fluorescence only. a) Bicompartmental fiber containing free acetylene groups in one compartment only, which was prepared by blending the PLGA with a poly[lactide-co-(propargyl glycolide)] ( $\approx 30$ wt.-\% of polymer). The acetylene-containing phase was further loaded with ADS306PT (red fluorescence), and the other compartment was labeled with ME-HPPV (blue fluorescence). The fibers were subsequently reacted with an azide-functionalized peptide via coppercatalyzed Huisgen 1,3-dipolar cycloaddition. The free amine groups of lysines in the peptide were finally reacted with a green-fluorescent dye (FITC) giving rise to green fluorescence in areas where the reaction occurred. Uniform peripheral green fluorescence due to FITC was seen alongside the red compartment only, indicating selective surface modification. b) Control fiber containing acetylene groups in both compartments, when subjected to identical conditions resulted in green fluorescence alongside both compartments. c) Fiber without acetylene groups did not exhibit significant green fluorescence indicating negligible non-specific binding of the peptide. Scale bars in $a, b$ and $\mathrm{c}$ are 20,20 , and $50 \mu \mathrm{m}$, respectively. 
bound to the red and blue compartments as evidenced by the uniform distribution of fluorescence originating from surface-conjugated FITC (Figure $3 b$ ). To exclude the possibility of non-specific binding of laminin peptide, microfibers without acetylene-PLGA were subjected to the copper-catalyzed Huisgen heterocycloaddition in the presence of peptide. Figure $3 c$ indicates negligible fluorescence signal corresponding to minimal non-specific adsorption of the peptide. This series of experiments confirmed that covalent immobilization of laminin peptide can be achieved in a spatially controlled fashion.

With selectively modified microfibers at hand, the biological function of microstructured fiber scaffolds could now be assessed in cell culture experiments. For this purpose, low-density microfiber scaffolds were deposited onto glass coverslips and selectively modified with laminin peptide. ${ }^{[40]}$ Bicompartmental microfiber scaffolds were modified by immobilizing laminin peptide in one or two compartments. In addition, bicompartmental microfibers without acetylene-PLGA in either one of the compartments, but treated with laminin peptide under copper-catalyzed Huisgen heterocycloaddition chemistry conditions and bicompartmental microfibers containing acetylene-PLGA in both compartments, but without peptide modification were used as negative controls. The four sets of samples were incubated with NIH 3T3 fibroblasts in serum-free media for $6 \mathrm{~h}$ followed by live-cell staining for actin. The microfibers were imaged using phase contrast microscopy and CLSM to observe relevant cell functions, such as cell spreading and cell orientation relative to the microfibers. In Figure 4, the CLSM images are shown along with insets representing the corresponding phase contrast images. Taken together, the images confirm cell adhesion to occur only on microfibers that were modified with laminin peptide (Figure $4 a$ and $b$ ). In the sample group, where only the red compartments have been modified with laminin peptide, cells adhere selectively to the red compartment (Figure 4a). Selective cellular contact guidance is unambiguously confirmed by the phase contrast images. Not surprisingly, bicompartmental microfibers, where both compartments have been surface-modified with laminin peptide, show rather uniform cell adhesion throughout the fiber scaffold (Figure 4b). Moreover, the CLSM images reveal that extensive cell spreading occurs only on fiber compartments that have been modified with the cell adhesion peptide, i.e., the red compartments for selectively modified microfibers (Figure 4a) and the red and blue compartments for uniformly modified fibers (Figure 4b). The cell adhesion a)

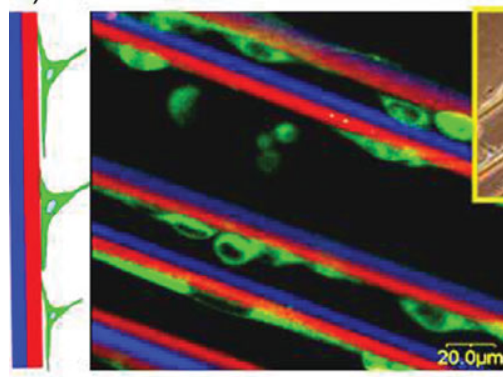

c)
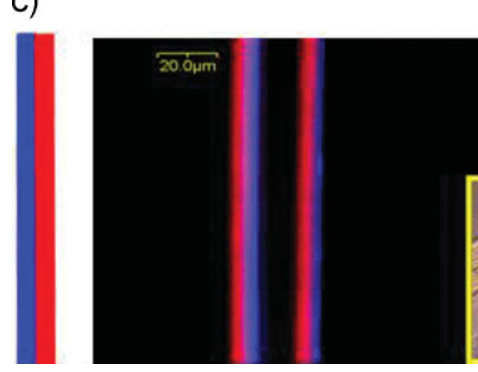
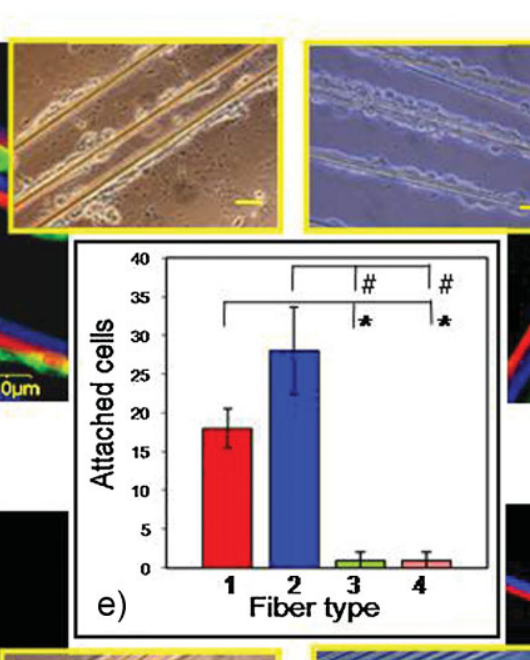

b)

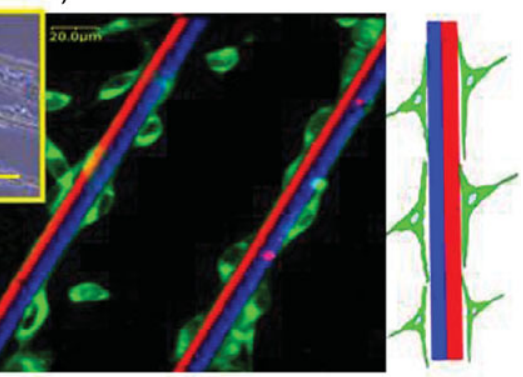

d)
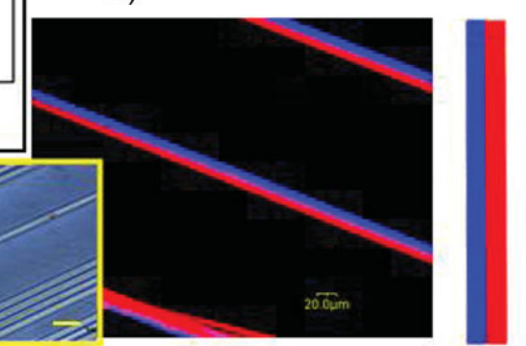

Figure 4. Guided cell adhesion on bicompartmental microfiber scaffolds selectively modified with a functional azide-peptide $\left(\mathrm{N}_{3}-\mathrm{CH} \mathrm{CONH}_{2}\right.$ CSRARKOAASIKVAVSADR) and incubated with fibroblasts. CLSM images as well as phase contrast micrographs (inserts) of bicompartmental microfibers are shown. a) Acetylene-PLGA was incorporated in the red compartment only followed by selective peptide conjugation resulting in cell adhesion alongside the red compartment only. b) Acetylene-PLGA introduced in red and blue compartments resulting in cell adhesion on both compartments. c) No acetylene-PLGA introduced in either compartment resulting in negligible cell adhesion. d) AcetylenePLGA in both compartments, but not conjugated with peptide resulting in negligible cell adhesion. e) Plot quantifying cell adhesion for each fiber type with data plotted as an average from five experimental sets. Bars 1, 2, 3, and 4 in the plot represent average number of cells ( \pm S.D.) attached to a standard length of fiber type described in a, b, c, and d respectively. ${ }^{*} p \leq 0.05$ for data set 1 when compared to set 3 and $4, n=5$. ${ }^{\#} p \leq 0.05$ for data set 2 , when compared to 3 and $4, n=5$. Scale bars in inserts represent $50 \mu \mathrm{m}$. 
and spreading on the microfibers in Figures $4 \mathrm{a}$ and $\mathrm{b}$ suggest that the fiber surface exhibited surface peptide ligands at a concentration sufficiently high to be recognized by the fibroblasts. In contrast, negligible cell adhesion is observed on surfaces that are void of the laminin peptide (Figure 4c and $\mathrm{d}$ ).

Next, cell adhesion was quantified for four groups corresponding to Figure $4 \mathrm{a}$ to $4 \mathrm{~d}$ by counting the number of cells per normalized length of fiber on the basis of phase contrast images. Data were plotted as an average of five trials (Figure 4e). The quantitative analysis indicates that the number of attached cells unambiguously depends on the peptide-modified surface area of the microfiber scaffolds. Samples modified with laminin peptide in either one or two compartments were significantly different from the sample groups without peptides $(p \leq 0.05)$. The average number of cells that attach to a bicompartmental microfiber with selective surface modification was $64 \%$ compared to a bicompartmental microfiber, where both compartments were modified with laminin peptide. Microfibers that were placed in close proximity of modified compartments of other fibers showed a higher number of nonspecifically attached cells than individual fibers placed in isolation, possibly due to multiple interactions between the cells and the ligands on the neighbouring fibers. In contrast, microfiber scaffolds with no acetylene-PLGA in either compartment, but subjected to copper-catalyzed Huisgen heterocycloaddition chemistry with the peptide, show only negligible cell adhesion on the fiber surface (Figure 4c). Similarly, microfibers with acetylene-PLGA in both compartments, but without peptide modification, did not support cell adhesion (Figure $4 \mathrm{~d}$ ). These control data confirm that cell adhesion indeed was caused by specific interactions between the cell receptors and the laminin peptide.

\section{Conclusion}

The ability to precisely control the internal architecture of microfiber scaffolds gives rise to a number of secondary control parameters, such as controlled chemical composition, optical anisotropy, or spatially controlled surface modification. Here, we successfully employed the latter aspect of bicompartmental microfiber scaffolds to design cell culture substrates for guided cell adhesion. However, before any new scaffold material can be used in a meaningful way in the context of complex biological systems, it will be critical to demonstrate that processing conditions that yield bicompartmental microfiber scaffolds are compatible with a wide range of biological molecules, such as growth factors, enzymes, or RNA. ${ }^{[41,42]}$ Development of encapsulation strategies, while preserving the biological activity of the biomolecules, ${ }^{[43]}$ will most likely become a key challenge to be addressed in future studies. Furthermore, though all multicompartmental fiber scaffolds have already been made of fully biodegradable polymers that are widely used for tissue engineering applications, ${ }^{[44,45]}$ future work will need to be directed toward applying the electrohydrodynamic co-spinning process to wider range of synthetic and natural polymers. In order to enable more meaningful functions in context of complex biological systems, differential interactions with heterogeneous populations of multiple cell types will need to be introduced to ultimately yield complex scaffold architectures, which are true mimicries of the biological materials they are intended to replace.

Acknowledgements: We thank Dr. Mutsumi Yoshida and Prof. David Martin, University of Michigan, for valuable discussions. J. L gratefully acknowledges financial support from the American Cancer Society.

Received: May 17, 2009; Accepted: May 19, 2009; Published online: July 29, 2009; DOI: 10.1002/marc.200900340

Keywords: biodegradable; biomaterials; co-electrospinning; surface immobilization; tissue engineering

[1] C. S. Chen, M. Mrksich, S. Huang, G. M. Whitesides, D. E. Ingber, Science 1997, 276, 1425.

[2] F. Rehfeldt, A. J. Engler, A. Eckhardt, F. Ahmed, D. E. Discher, Adv. Drug Deliv. Rev. 2007, 59, 1329.

[3] D. Lehnert, B. Wehrle-Haller, C. David, U. Weiland, C. Ballestrem, B. A. Imhof, M. Bastmeyer, J. Cell Sci. 2004, 117, 41

[4] M. J. Dalby, M. O. Riehle, D. S. Sutherland, H. Agheli, A. S. G. Curtis, Eur. J. Cell Biol. 2004, 83, 159.

[5] H. J. Kong, S. Hsiong, D. J. Mooney, Nano Lett. 2007, 7, 161.

[6] M. Arnold, V. C. Hirschfeld-Warneken, T. Lohmuller, P. Heil, J. Blummel, E. A. Cavalcanti-Adam, M. Lopez-Garcia, P. Walther, H. Kessler, B. Geiger, J. P. Spatz, Nano Lett. 2008, 8, 2063.

[7] S. Mitragotri, J. Lahann, Nat. Mater. 2009, 8, 15.

[8] D. B. Weibel, W. R. DiLuzio, G. M. Whitesides, Nat. Rev. Micro. 2007, 5, 209

[9] R. S. Kane, S. Takayama, E. Ostuni, D. E. Ingber, G. M. Whitesides, Biomaterials 1999, 20, 2363.

[10] L. Cao, D. J. Mooney, Adv. Drug Deliv. Rev. 2007, 59, 1340.

[11] N. Xia, C. K. Thodeti, T. P. Hunt, O. B. Xu, M. Ho, G. M. Whitesides, R. Westervelt, D. E. Ingber, FASEB J. 2008, 22, 1649.

[12] M. M. Stevens, J. H. George, Science 2005, 310, 1135

[13] V. L. Tsang, S. N. Bhatia, Adv. Drug Deliv. Rev. 2004, 56, 1635.

[14] R. Murugan, S. Ramakrishna, Tissue Eng. 2007, 13, 1845.

[15] J. Lee, Tissue Eng. Part B Rev. 2008, 14, 61.

[16] G. C. Engelmayr, M. Cheng, C. J. Bettinger, J. T. Borenstein, R. Langer, L. E. Freed, Nat. Mater 2008, 7, 1003.

[17] J. Venugopal, S. Low, A. T. Choon, S. Ramakrishna, J. Biomed. Mater. Res. Part B Appl. Biomater. 2008, 84B, 34. 
[18] I. K. Kwon, S. Kidoaki, T. Matsuda, Biomaterials 2005, 26, 3929.

[19] C. P. Barnes, S. A. Sell, E. D. Boland, D. G. Simpson, G. L. Bowlin, Adv. Drug Deliv. Rev. 2007, 59, 1413.

[20] Z. W. Ma, M. Kotaki, R. Inai, S. Ramakrishna, Tissue Eng. 2005, 11, 101.

[21] J. Xie, X. Li, Y. Xia, Macromol. Rap. Comm. 2008, 29, 1775.

[22] T. J. Sill, H. A. von Recum, Biomaterials 2008, 29, 1989.

[23] J. E. Sanders, S. D. Bale, T. Neumann, J. Biomed. Mat. Res. 2002, 62, 222.

[24] O. P. Pham, U. Sharma, A. G. Mikos, Tissue Eng. 2006, 12, 1197.

[25] S. Bhaskar, J. Lahann, J. Am. Chem. Soc. 2009, 131, 6550.

[26] S. Bhaskar, K. H. Roh, X. Jiang, G. L. Baker, J. Lahann, Macromol. Rapid Commun. 2008, 1655.

[27] A. Papra, N. Gadegaard, N. B. Larsen, Langmuir 2001, 17, 1457.

[28] P. Gupta, G. L. Wilkes, Polymer 2003, 44, 6353.

[29] R. P. A. Hartman, D. J. Brunner, D. M. A. Camelot, J. C. M. Marijnissen, B. Scarlett, J. Aerosol. Sci. 2000, 31, 65.

[30] K. H. Roh, D. C. Martin, J. Lahann, Nat. Mater. 2005, 4, 759.

[31] K. H. Roh, D. C. Martin, J. Lahann, J. Am. Chem. Soc. 2006, 128, 6796.

[32] K. H. Roh, M. Yoshida, J. Lahann, Langmuir 2007, 23, 5683.

[33] M. Yoshida, K. H. Roh, J. Lahann, Biomaterials 2007, 28, 2446.
[34] M. Cloupeau, B. Prunet-Foch, J. Electrostat. 1989, 22, 135.

[35] D. H. Reneker, A. L. Yarin, H. Fong, S. Koombhongse, J. App. Phys. 2000, 87, 4531.

[36] S. Bhaskar, J. Hitt, S. L. Chang, J. Lahann, Angew. Chem. Int. Ed. 2009, 25, 4589

[37] X. Jiang, E. B. Vogel, M. R. Smith, G. L. Baker, Macromolecules 2008, 41, 1937

[38] Z. P. Demko, K. B. Sharpless, Angew. Chem. Int. Ed. 2002, 41, 2113.

[39] H. Nandivada, X. W. Jiang, J. Lahann, Adv. Mater. 2007, 19, 2197.

[40] L. Kam, W. Shain, J. N. Turner, R. Bizios, Biomaterials 2002, 23, 511.

[41] E. K. Moioli, L. Hong, J. Guardado, P. A. Clark, J. J. Mao, Tissue Eng. 2006, 12, 537.

[42] X. H. Zhu, C. H. Wang, Y. W. Tong, J. Biomed. Mater. Res. A 2008, $89 A, 411$.

[43] A. Giteau, M. C. V. Julienne, S. M. J. L. Courthaudon, M. Sergent, C. M. Menei, J. M. Verdier, J. P. Benoit, Eur. J. Pharm. Biopharm. 2008, 70, 127.

[44] D. S. Kohane, R. Langer, Pediatr. Res. 2008, 63, 487.

[45] A. Khademhosseini, R. Langer, J. Borenstein, J. P. Vacanti, Proc. Natl. Acad. Sci. USA 2006, 103, 2480. 